\title{
On the approaches to self-knowledge.
}

\section{Introduction}

Vague guesses about the veritable evolutionary essence of terrestrial organisms, which are not divine creatures at all, but simple bio-robots, haunted mankind for a long time. And even, by the way, that pretty piquant alignment for us, at which "his majesty" Homo sapiens can also personify some type of artificial, and not really existing hypostasis, was discussed at one time as by solipsists (Lao-tzu, Buddha, Gorgias, Claude Brunet), as other famous sages of antiquity; but, a true, in a somewhat different perspective.

However, in serious science, mere pompous tirades are clearly not enough instead specific arguments were required. And exactly one and a half centuries ago* in St. Petersburg an epoch-making, one might say without exaggeration, book "Reflexes of the Brain" was published, where all this evidence was clearly and quite convincingly presented. And although against the very "father of Russian physiology" I.M. Sechenov, many of the then religious leaders immediately took up arms, accusing him of blasphemy, immorality and other grave, inexorable sins, however, the corresponding initiation, as the saying goes, was successfully laid, and besides reliably documented. With which, by the way, the majority of the world scientific community agreed in the end too. While already in the middle of the next century, these progressive ideas of our illustrious compatriot were maintained by Jewish emigrant Norbert Wiener, who practically equated any living creature with a machine.

But, be that as it may, in own new philosophical treatise the author makes a bold attempt to penetrate even deeper to the most secret labyrinths of the spiritualized nature - with the mind's eye scanning the intracellular space and substantiating thus the entire complex evolutionary mechanism of optimal program control in the system of higher nervous regulation.

Yes, indeed, there is really no need to argue here: we are all aesthetically graceful, morally perfect and, besides, quite lettered bio-robots! But just why, however, many in practice are so wary, and sometimes even belligerent about this? It turns out, because in the sphere of the vast majority of post-Soviet republics' humanitarian education, the banal Marxist-Leninist materialism still reigns supreme. The true idealistic wing (I emphasize: not religious but research one), in fact, simply does not exist - except perhaps for a few single enthusiasts like N.P. Bekhtereva, V.I. Tsymbalyuk, V.D. Mishiyev, Y.P. Zinchenko. And although new advanced knowledge has begun to pour out into society by a runaway rapid stream, however, in our opinion, adequate state support is still not enough for it.

Well, then let's try at least in given theoretical review, to correct as far as possible_such unpleasant tendency.

As known, human memory functions on several levels, and primary (which localized in the dominant thalamus) is directly related to sensory imprinting. It's essentially the involved here monads' memory. A few seconds later, emotionally colored informational sensations can still be restored in consciousness due to reverberation of nerve impulses along the contour of thalamic nuclei or even on the overlying brain layers (if it is about, for example, the perception of speech, gestures, hieroglyphs and other difficult abstract images). Such memory can be named momentary. Generally, the limbic structures, including the hippocampus, are able to 
accept not only targeted orders from the thalamus, but also to catch the emotional background of any symbolically encoded messages which arrive in suitable for assimilation kind from the cortex. Wherein the hippocampus is responsible for the functioning of human working memory too.

As mentioned earlier, in the course of the historical evolution of natural systems, continuity is quite distinctly traced both in the character itself and in the way of forming sensations and emotions specific to this particular stage. But still it's most clearly seen in the example of memory, because the short-term memory of each subsequent system holds on to the remembrance substrate of the previous one. By the by, momentary (reverberative) memory is also apparently present at any step of the evolutionary hierarchy. But it mainly depends on the nature of the imprinting and methods the signals are transmitted, and not on the underlying structures because systems of different levels perceive the passage of time (and hence the very chronology of events) unequally.

Despite the fact that a long-term memory of chordates is based, in principle, on astrocytes, yet, if necessary, it's quite capable of appealing to similar memosubstance of a lower order represented, obviously, by intranuclear (but sometimes, possibly, even extracellular) proteins ${ }^{\star \star}$. However in all people without exception, long-term memory (confined - recall just in case - to the gray matter of the cortex of both hemispheres) is generated from the working one and moreover, as a rule, during minutes of sensory lull, i.e. basically in the afternoon. At night it only is completed what was not done in daylight hours (and unless in separate short "stripes" because most of the time the brain just rests).

Although astrocytes (which, as you know, have a much shorter evolutionary "experience") store their database in analog form, and peptides - in digital, both of these functions all the same are strictly selective. Particularly, in the course of the selection of more important material, concept-proteins already present in neurons obviously play leading role, and the subcortical structures responsible for working memory are secondary. Wherein the phenomenon of total memorization is inherent only in the primary monadiform "Self" (and even then not everyone is able to get such information).

II.

Human thinking is based on long-term memory and is formed in areas directly adjacent to the corresponding sensory analyzers of the cerebral hemispheres. The same concepts, which is quite natural, are capable of being duplicated several times, depending on their etiological background. In addition, one should consider the possible ramification of notions not only in the sensory aspect, but also at a higher ordinal level: as homonyms, synonyms, idioms, neologisms, and even by purely emotional signs. At that new astrocytic \& protein notions are built (with reference, of course, to the material already available here) on the basis of fresh relevant images worthy of entering into long-term memory.

In the thickness of the cerebral hemispheres, just like in complex cyber devices or propositions of formal logic, hierarchical pyramids are located, at the very top of which super-concepts lie. Besides, here are present as well analogues of the categorical-semantic apparatus, associative zones, structures responsible for the functioning of the feedback principle etc. By the way, within formal logic, one might say, there is nothing at all that would not be somehow realized in the brain of highly developed representatives of the earthly fauna. For_instance, using the wellknown law: "If $B$ follows from $A$, then non-A follows from non- $B$ ", we must be 
prepared to find "the non-B protein" directly linked to "the non-A protein". Of course, in order to save space, such abstract structures are laid mainly at the level of super-concepts.

Specific "departmental" chromosomes are responsible for the connection between individual protein-concepts, whilst the neurons themselves are for the formation of the resulting associative tracks, using, all appearance, ordinary electrical impulses for this (in contrast to the sound signals of their nucleic precursors by the system hierarchy). These neurons can work at any time, regardless of the involvement in the area of consciousness, but basically they do it during the day, in the waking period. When the long syllogistic chain "protein $A$ protein B - protein C - protein D" is closed by means of "protein A - protein D", cells are excited, which, as we know, leads to the release of additional portions of energy. Energy, being converted into a nerve impulse, reaches the thalamus, but it is not always properly perceived there. When this signal is irrelevant to the organism, the "Ego" does not react to it. Although in other cases, our "main post" singly can send a request to the cortex, if he needs to remember something or urgently find an answer. Such way of communication is, at least, much more effective.

As for astrocytes, they here (and above all - in the folds of gray matter) act only as passive albeit rather reliable keepers of memory. At that, as mentioned earlier (see the previous section), the author is inclined to believe that it is analog in nature, not digital, being directly caused by the close biochemical interaction between glia- and neuro-transmitters.

\section{III}

Thus, in contrast to instant recognition with sensory implications, all other memo-images (i.e., not related to the acute immediate needs of an individual) owe their genesis exclusively to the cortex. Although they are transmitted, perhaps, by the quantum-wave path but even so are projected into human consciousness for sure through a material (or rather, monad) substrate that is quite familiar to us. Moreover practically the same should be said about all sorts of dreams, fantasies, complex multi-stage abstractions, and, of course, about any mentally creative processes that are characteristic, in one way or another, for serious scientific developments. By and large, their implementation, in fact, is not much different from similar previously described phenomena, occurring in the sensory nuclei, but here, however, it still cannot do without the direct active participation of higher cerebral structures. Firstly, an abstract image of the observer is created, from the point of view of which the represented object is considered; secondly, here every now and then it is also necessary to involve, besides, such formal categories as magnitude, dimension, angle of perception, etc. All these operating procedures are the paramount vital concern of thinking, while the finally created image is transferred into the central "Self". Although the latter, at the same time, it would hardly be correct to assign some minor, purely facultative role in these processes. And here, for example, is visual confirmation of what was said: it has long been well known that weak-willed people, as a rule, do not have stable and sufficiently strong thought associations. The images arisen in them are unsteady, vague and quickly disappear from consciousness, again and again replaced by some new ones...

In addition, the general nature of the produced cognitive representations may also depend on the concrete emotional attitude, the specific hemispherity of a given person, the degree of development of cerebral cytomyeloarchitectonics and a number of other important factors. 


\section{IV}

Well, in the finishing section, let's still try to find out, due to what, at the level of an individual or even humanity as a whole, such an amazing natural phenomenon as self-conscience is realized.

First of all, it should be clarified here that without proteins and astrocytes, neither the genome, nor the primary "Ego", nor the thalamus by themselves would probably ever have guessed about their fleshly existence. So, it only looks like some insignificant detail, because in translation into epistemological language, one might say that such important scientific disciplines as psychology, biomedicine (namely, in the context of the genesis of the spiritualized planetary matter and its radical difference from inert), ethics, jurisprudence, and many other truly fundamental branches. In historical terms, some vague glimpses of self-awareness have arisen among those primitive savages who have been able to compare the fact of the death of close friends, neighbors and relatives with the fatal inevitability of own demise.

But still it would be, of course, wrongfully and even illogical to give some exclusive role to proteins alone here. After all, in fact, already in the early author's works, it was quite rightly noted that the most important necessary and sufficient prerequisites for the emergence of such a significant process for earthly evolution should be considered: a) the presence of at least two mentally similar persons in a limited area of habitation; b) an increase in early representatives of the tribe Homo starting from Australopithecus - of the degree of generalizing thoughtful operations to the conceptual level (moreover, apparently, one can say that extrasensory perception or gestural language in this case, for sure, does not work); and, finally, the birth of the so-called second signaling system. By the way, the term "process" itself is used here by no means accidentally, because it directly and unequivocally denies the idea of an explosive appearance or even (as, for example, some of our hugely popular among the ignorant masses of pseudo-authorities talk about this) "export" of such cognitive reflection from somewhere outside. On the off-chance, let us recall once again in this regard that according to the ground axiom of formal logic about the impossibility of cognizing the subject by the subject, any arbitrarily 
developed creature (even up to aliens or super-humanoids from other planets), being lonely, is fundamentally unable to master the factor of self-awareness. In addition, the problem of potential grassroots self-identification is also of considerable interest here, because any unprejudiced investigator, by and large, would probably be care at all to know whether, say, the ordinary thermal neutrons or some other long-lived particles possess by this native gift. For we have no right to mechanically extrapolate to them the arguments that are fashionable nowadays about a certain obligatory minimum of accumulated information and on this basis without hesitation to disown such an important attribute of the vital activity of any organized matter. Not only is one information different from another, but yet absolutely nobody has proven that those bits which are embedded in each monad or perimonadic structures are beneficial to a person. Maybe the human mind is able to refer exclusively to the cellular chromatin, and the monads of one particular nitrogenous base or amino group carry two kinds of information: polytypic - for own local purposes and unified - for some universal needs?! So in this case it is difficult, perhaps, to immediately find $100 \%$ accurate answer: after all, the range of issues touched upon here is already far beyond the scope of any of the natural sciences, acquiring, in fact, a pronounced philosophical orientation.

There is another paradox, not so acute and burning, but still worthy of at least briefly illuminating it at the proper level. The point is that any actively cognizing subject, on the one hand - a purely formal - understands nobody and nothing as well as himself; while on the other - contentual - he will never be able to get as complete and exhaustive information about himself as about the physical bodies around him. Which he, if desired, at any time can touch, disassemble into parts, look inside and even remake on his own way.

\section{A final summary}

Here, perhaps, is all that can be said for today about the launch and implementation of the most complex thought mechanisms at the level of individual human being and the dominant, truly invaluable role of protein macro-molecules (such seemingly alien in relation to our vital nucleotide chains) in this process. As for the entire planetary mankind, it eventually in full realizes its essence and purpose also except with the help of robots. It is interesting that both proteins and highly organized robots from the not so distant future are able to accumulate and 
analyze information about external world, in fact, even without any support from DNA or, respectively, modern scientific community. Therefore, here once again the hypothesis proposed by us earlier (the essence of which is that the evolution of cosmic intelligence in its rates is noticeably ahead of the evolution of living natural systems) is confirmed in actuality. And thus, only in human society (after all, some tailless upright walking specimen torn out of it, does not mean anything, alas, in itself) for the mature earthly mind - as the only effective tool on the way to find the truth - the far-reaching and very attractive prospects are prepared!

\footnotetext{
*This refers to the second edition of the pamphlet of 1871, since the first (1866) was arrested and fully withdrawn from sale by the tsarist censorship.

**However, it's not excluded that professional magicians and wonderworkers might even turn to amino-groups for the necessary information, and also to gluons, mesons, etc. (as if plunging into the truly bottomless mnemo-storage of downward systems).
} 